\title{
Racializando o olhar (sociológico) sobre a saúde ambiental em saneamento da população negra: um continuum colonial chamado racismo ambiental'
}

\section{Racializing the (sociological) view on environmental health in the sanitation of the black population: A colonial continuum called environmental racism}

\author{
Victor de Jesus ${ }^{\mathrm{a}}$ \\ (i) https://orcid.org/0000-0001-7623-9948 \\ E-mail: victordejesuscsoळgmail.com \\ aUniversidade Federal do Espírito Santo. Programa de Pós-Graduação \\ em Ciências Sociais. Vitória, ES, Brasil.
}

\section{Correspondência}

Victor de Jesus

Rua Natalino Ribeiro, $3^{\text {a }}$ etapa, Quadra V, Bloco 504-A, Ap. 202. Serra, ES, Brasil. CEP: 29172-625.

\section{Resumo}

O déficit de saneamento - e seu impacto à saúde - é uma realidade de parcela significativa da população brasileira. No entanto, essa desigualdade não é distribuída de forma equânime na sociedade, há um perfil racial daqueles mais vulneráveis e vitimados pelas condições ambientais insalubres. Apesar de constituir um problema social, essa temática ainda tem sido negligenciada enquanto problema sociológico. Desse modo, a partir da pesquisa bibliográfica de nível exploratório e da análise de dados atuais de acesso a saneamento e morbimortalidade por doenças relacionadas ao saneamento ambiental inadequado segundo cor/raça, pretendeu-se racializar a discussão sobre saneamento e saúde (ambiental) a partir de uma perspectiva político-histórica. Verificou-se que desde o Brasil Colonial há um continuum de vivências sanitárias da população negra marcado pelo não acesso aos serviços de saneamento e seu consequente impacto na saúde ambiental dessa população. Em virtude disso, a cada uma hora e meia uma pessoa negra morre por não ter saneamento adequado no Brasil, uma realidade que resulta da relação entre Estado, racimo institucional e racismo ambiental e contribui para o genocídio da população negra brasileira. Urge, portanto,

I Pesquisa financiada pelo Conselho Nacional de Desenvolvimento Científico e Tecnológico (CNPq). 
olhares e ações que coloquem esse tema nas agendas políticas e de pesquisa.

Palavras-chave: Racismo Ambiental; Saneamento; Saúde Ambiental; Saúde da População Negra; Higienismo; Genocídio Negro.

\section{Abstract}

The deficit of sanitation and its impact on health is a reality of a significant part of the Brazilian population. However, this inequality is not equitably distributed in society, as there is a racial profile of those most vulnerable and victimized by unhealthy environmental conditions. Although it is a social issue, this subject has still been neglected as a sociological problem. Thus, based on an exploratory-level bibliographic research and the analysis of current data on access to sanitation and morbidity/mortality from diseases related to inadequate environmental sanitation according to color/race, this paper includes the factor of race on sanitation and health (environmental) discussion from a political-historical perspective. The results show that since Colonial Brazil there is a continuum of sanitary experiences of the black population marked by the lack of access to sanitation services and their impact on the environmental health of this population. As a result, every 1 h3o a black person dies for not having adequate sanitation in Brazil, a reality that results from the relationship between State, institutional racism and environmental racism, contributing to the Brazilian black genocide. As such, perspectives and measures that place this topic in the political and research agendas are urgent.

Keywords: Racial Hygiene; Environmental Racism; Sanitation; Environmental Health; Black Population Health; Black Genocide.

\section{Introdução}

Atualmente, compreende-se como saneamento básico o conjunto de serviços, infraestruturas e instalações operacionais de limpeza urbana e manejo de resíduos sólidos, drenagem e manejo das águas pluviais urbanas, esgotamento sanitário e abastecimento de água potável. Saneamento ambiental, por sua vez, compreende o saneamento como instrumento de promoção à saúde que, além do saneamento básico, inclui os resíduos gasosos, a promoção da disciplina sanitária de uso do solo, o controle de doenças transmissíveis e demais serviços e obras cuja finalidade seja a qualidade de vida e bem-estar urbano e rural (Brasil, 2007; Funasa, 2015).

Desse modo, torna-se evidente a estreita relação entre saneamento, saúde e meio ambiente, cuja relevância e comprovação estão evidenciadas na existência de áreas e conceitos como epidemiologia ambiental, saúde ambiental, salubridade ambiental e promoção de saúde, ainda que na prática o planejamento não seja integrado (Funasa, 2015; Heller, 1998; Soares; Bernardes; Cordeiro Netto, 2002). Merece atenção ainda o conceito de saúde ambiental em saneamento, que se refere à promoção da saúde e qualidade de vida da população por meio das ações em saneamento e intervenções em educação, conforme o Manual de saneamento (Funasa, 2015).

No arcabouço legal, a saúde ambiental em saneamento é assegurada tanto a nível nacional quanto internacional. Constitucionalmente (Brasil, 1988), a saúde é assegurada como direito de todos e dever do Estado (art. 196), sendo a participação na formulação da política de saneamento e a execução das ações do setor (art. 200) como parte do escopo do Sistema Único de Saúde (SUS). Já o direito ao meio ambiente ecologicamente equilibrado é garantido como requisito para a sadia qualidade de vida das presentes e futuras gerações (art. 225). Já o direito ao saneamento e à saúde ambiental, bem como a universalização do acesso ao saneamento básico, são instituídos pela lei 11.445/2007 (Brasil, 2007), conhecida como lei do saneamento básico por estabelecer as diretrizes do setor. 
No entanto, a saúde ambiental em saneamento enquanto direito não garante o seu cumprimento legal. Em virtude desse aspecto, as discussões sobre determinantes sociais da saúde, iniquidades em saúde e justiça ambiental têm contribuído de forma significativa na politização dos processos sociais de saúde-doença, denunciando o caráter injusto, evitável, inaceitável e desumano que acomete as condições de saúde de alguns segmentos sociais situados em contextos espaciais de desigualdades socioeconômicas, ambientais e culturais (Barata, 2001, 2009; CNDSS, 2008; Porto, 2004).

Assim, a falta de acesso à moradia digna e ao saneamento emergem como determinantes do processo saúde-adoecimento no país (Brasil, 2010; CNDSS, 2008) e, consequentemente, produzem quadros epidemiológicos cujos perfis predominantes são grupos destituídos de poder e propriedade (Barata, 2001, 2009). Nesse sentido, algumas autoras têm destacado que a população negra ${ }^{2}$ constitui um desses grupos vulnerabilizados e ressaltado a necessidade de pesquisas sobre as condições de saneamento e seu impacto na saúde da população negra (Cunha, 2012; Garcia, 2009; Lopes, 2005a, 2005b; Rosemberg; Pinto, 1995; Santos, 2013), já que o enfoque na relação saneamento e raça é bastante limitado ${ }^{3}$ na bibliografia nacional. E, quando o fazem, as pesquisas não trazem o contexto histórico, tampouco a colocam na discussão teórica e política do racismo (estrutural, institucional, ambiental). Aliás, a própria discussão sobre racismo ambiental no Brasil é ainda muito insipiente e somente mais recentemente a discussão sobre racismo institucional tem ganhado força.
Somado a isso, não se deve perder de vista que, numa escala maior, a variável racial e a discussão sobre racismo e desigualdades raciais no campo da epidemiologia e da saúde pública, bem como o diálogo com a interface ambiental, seguem negligenciadas nas agendas hegemônicas de pesquisa das ciências sociais em saúde, de tal modo que colocam demandas como fomento de pesquisas sobre o quadro epidemiológico da população negra, abordagem, identificação e combate às formas de racismo institucional e identificação das necessidades de saúde da população negra das áreas urbanas (Barata, 2009; Bastos; Faerstein, 2012; Brasil, 2013; Cunha, 2012; Lopes, 2005a, 2005b; Soares Filho, 2012; Werneck, 2016).

Este artigo, portanto, visa preencher (sem a pretensão de esgotar) essa lacuna, na medida em que busca ressaltar a importância da variável racial na análise da relação saneamento e saúde e situar essa temática na discussão sobre racismo ambiental a partir de uma perspectiva políticohistórica que realce a importância das doenças de saneamento na composição do quadro de morbimortalidade da população negra. Assim, racializar a discussão sobre saneamento e saúde (ambiental) e politizar a discussão sobre racismo constituem o mote deste artigo.

Ademais, implicitamente objetiva-se elevar esse problema social a problema sociológico, isto é, empreender um esforço de pesquisa que o coloque como um problema científico e como alvo de políticas sociais, como assinala Silva (1967). Para isso, é importante considerar que a pesquisa científica precisa estar relacionada à vida real e aos interesses e circunstâncias sociais, pois "nada pode

\footnotetext{
2 Metodologicamente, refere-se à população negra como a soma de populações autodeclaradas pretas e pardas nos formulários e pesquisas como os Censos do IBGE ou prontuários de saúde, por exemplo. Para isso, inclui-se um campo no qual a categoria cor é escolhida entre as opções preta, parda, branca, amarela ou indígena. Sociologicamente, compartilho da posição de Munanga (2003), para quem raça referese aos aspectos culturais e identitários construídos historicamente e reelaborados enquanto construtos sociais e políticos nas relações de poder, não como fator biológico, científico e determinista. Para o autor, raça e etnia são conceitos ideologicamente manipulados hoje, servindo a vários e confusos usos.

3 Não estou desconsiderando a existência de inúmeras etnografias e estudos sociológicos que trazem alguma descrição ou dado sobre saneamento em aldeias e comunidades indígenas ou quilombolas, ou ainda em periferias e favelas, e sua interface racial; tampouco alguns estudos do governo federal, como Retratos da desigualdade, do Instituto de Pesquisas Econômicas Aplicadas (Ipea). Ao falar do número limitado de pesquisas dessa relação, refiro-me àquelas cujo objetivo seja especificamente o de tratar dessa dimensão racial do déficit em saneamento, com aporte teórico que dê conta de aprofundar a compreensão sociológica desse problema social.
} 
ser intelectualmente um problema se não tiver sido, em primeiro lugar, um problema da vida prática" (Minayo, 2012, p. 16).

Nesse sentido, convém apontar que este artigo foi produzido a partir de questões-incômodos de minha experiência individual durante a ida para o Rio de Janeiro nos dois anos de mestrado. $\mathrm{Na}$ "cidade maravilhosa" vivenciei problemas cotidianos oriundos da falta de saneamento, desde baixa pressão e falta d'água à não utilização da água por sair excessivamente quente da caixa, passando ainda por convívio com o excesso de lixos, ratos e baratas. A preocupação de chover e não ter como entrar em casa, sair de casa sem poder tomar banho, neurose em fechar todos os buracos possíveis para não entrar barata e enchimento de vasilhas d'água na universidade para consumir em casa foram algumas experiências que marcaram minha passagem pelo Rio de Janeiro. Essa narrativa é minha, mas não só minha.

Longe de ser um problema individual e uma realidade oculta, essa é uma realidade social evidente e facilmente verificável quando se anda em periferias, favelas, subúrbios e quebradas. Em face disso, busco, portanto, a macroescala, os dados gerais que alcem esse fenômeno social a problema sociológico de abrangência nacional. Para isso, utilizo-me da pesquisa bibliográfica de nível exploratório, conforme sugere Gil (2009), na medida em que constitui uma apropriação de material já elaborado, sobretudo livros e artigos científicos, para produzir uma visão geral e aproximativa sobre o fato, sobretudo quando o tema é pouco explorado, a fim de recolocar o problema sob um novo prisma. Além disso, analiso os dados atuais de acesso a saneamento e morbimortalidade por doenças relacionadas ao saneamento ambiental inadequado segundo cor/raça, utilizando as bases de dados do Censo 2010, do IBGE, e do Tabnet DataSUS, do SUS.

Inicio com uma reflexão sobre o que se entende por racismo institucional e qual sua relação com a saúde. Em seguida, abordo o racismo ambiental como uma dimensão do racismo institucional e sua relação com o saneamento e a insalubridade ambiental. Por fim, situo a histórica e colonial relação da população negra com o não acesso a saneamento e seu impacto na morbimortalidade dessa população.

\section{o racismo institucional como determinante social da saúde}

O racismo pode se apresentar de múltiplas e complexas formas, incluindo desde sentimentos pessoais e ações interpessoais à estruturação de políticas públicas, governos e Estados, moldando cultura, política e ética. Ou seja, basicamente, o racismo pode ocorrer nos níveis pessoal (internalizado), interpessoal e institucional, sendo este o que nos interessa aqui, por ser a dimensão mais negligenciada do racismo (Geledés, 2013a; Werneck, 2016).

O racismo institucional, também denominado de racismo sistêmico, corresponde ao mecanismo estrutural de exclusão racial seletiva no acesso aos benefícios gerados pelo Estado e usufruídos pelos grupos raciais privilegiados. Desse modo, o racismo institucional induz, mantém e condiciona a organização e a ação do Estado, suas instituições e políticas públicas (Brasil, 2013; Geledés, 2013a). Isto é, o racismo institucional é responsável por promover a exclusão seletiva dos grupos raciais subordinados por meio de "lógicas, processos, procedimentos, condutas, que vão impregnar a cultura institucional - o que, se não os torna invisíveis, faz parte da ordem 'natural' das coisas" (Werneck, 2016, p. 545).

Esse tipo de racismo pode ser verificado tanto no acesso ao poder quanto na dimensão material, sendo esta a de maior interesse aqui, que pressupõe a ausência reiterada do Estado, em alguns casos, e/ou a indisponibilidade ou limitação ao acesso a direitos fundamentais, serviços e políticas de qualidades. Ou seja, o racismo institucional é responsável por perpetuar privilégios, hegemonias brancas e condições estruturantes das desigualdades raciais que expõem a população negra às condições de vulnerabilidade e desproteção social (Geledés, 2013a, 2013b).

É nesse sentido que o racismo emerge como determinante social da saúde, na medida em que a concentração de riqueza e poder, bem como as condições ambientais e de vida e o fator raça, 
está associada às iniquidades em saúde. Assim, a compreensão do racismo como determinante social da saúde implica o reconhecimento de que o racismo institucional constitui um entrave à promoção da equidade na medida em que influencia o processo saúde-doença-cuidado-morte, favorece um quadro de morbimortalidade por doenças injustas e evitáveis e estimula a violação dos direitos humanos (Barata, 2009; Bastos; Faerstein, 2012; Brasil, 2011; Lopes, 2005a, 2005b; Soares Filho, 2012; Werneck, 2016).

Isso fica evidente ao analisar os números de mortalidade (infantil e adulta), expectativa de vida e anos de vida perdidos segundo raça, que configuram um quadro de marcas visíveis e mensuráveis de desesperança de vida ao nascer e de perda superlativa de vidas por causas externas de morte, tendo no racismo um fabricante e multiplicador de vulnerabilidades que faz com que indígenas ${ }^{4} \mathrm{e}$ negros tenham experiências desiguais de nascer, viver, adoecer e morrer, quando comparados com os brancos (Lopes, 2005a, 2005b).

Essa situação também foi denunciada na Conferência de Durban ${ }^{5}$ (2001), na qual apontaram o racismo e a discriminação racial como fatores de deterioração da condição de vida e de negação dos direitos humanos. Em 2013, a Política Nacional de Saúde Integral da População Negra (PNSIPN) fez o "reconhecimento do racismo, das desigualdades étnico-raciais e do racismo institucional como determinantes sociais das condições de saúde, com vistas à promoção da equidade em saúde" (Brasil, 2013, p. 18), embora essa política não tenha sido adequadamente implementada e seja até rechaçada por muitos (Werneck, 2016).

É importante ressaltar que esse contexto não está dissociado das condições políticas, sociais e econômicas que estruturam as relações e negociações na sociedade. As condições precárias em que vive a população negra e pobre moldam um quadro de condições de vida estruturado em "injustos processos sociais, culturais e econômicos presentes na história do País” (Brasil, 2013, p. 5), onde prevalecem doenças crônicas e infecciosas, altos índices de violência urbana, altas taxas de mortalidade materna e infantil e uma situação de "indignidade das condições de vida da população negra”, desprovidas de bens e serviços públicos e marcadas pela exclusão social.

Assim, alguns estudos relativos às desigualdades sociais em saúde têm demonstrado maior desvantagem social à qual a população negra está submetida, incluindo as condições de pobreza, o baixo índice de desenvolvimento humano e o acesso precário a saneamento básico, educação e postos de trabalho (Barata, 2009; Bastos, Faerstein, 2012). Um cenário de desvantagens que inclui ainda “discriminação econômica, segregação espacial, exclusão social, destituição do poder político e desvalorização cultural” (Barata, 2009, p. 66).

\section{Saneamento e insalubridade ambiental em contextos de racismo ambiental}

Compreendendo o racismo institucional como a "negligência" do Estado na garantia de serviços, obras, políticas públicas e direitos humanos (básicos e fundamentais), verifica-se a existência de uma relação entre racismo institucional e saúde ambiental em saneamento no que diz respeito à saúde, ao meio ambiente ecologicamente equilibrado e ao saneamento básico.

Historicamente, as populações pobres, despossuídas e pertencentes a minorias étnicoraciais $^{6}$ têm sido alocadas próximas a instalações de esgoto e lixo e expostas a condições inadequadas

\footnotetext{
4 É importante destacar que, apesar do enfoque na população negra, as populações indígenas também têm sido impactadas pelo racismo ambiental em condições sanitárias ainda mais precárias em termos relativos, sobretudo os domicílios indígenas em área urbana, conforme aponta Raupp (2017). Em virtude desse cenário, as doenças infecto-parasitárias possuem grande impacto sobre a saúde indígena, sobretudo em crianças menores de 5 anos, cuja morbimortalidade por diarreia tem historicamente vitimado (CNDSS, 2008). 5 Marco internacional sobre o racismo.

6 Há pesquisadoras(es) que utilizam o termo étnico ou étnico-racial para contemplarem também a diversidade (étnica) dentro do próprio grupo racial - por exemplo, bantos e criolos são etnias negras. A categoria "étnico" é muito utilizada quando a discussão inclui os indígenas, para diferenciar e valorizar os diversos grupos, como tupiniquim e guarani. Munanga (2003) lembra que raça tem um conteúdo
} 
de saneamento em virtude de políticas ambientais discriminatórias. Merece destaque o caráter racial desse processo, na medida em que alguns grupos estão mais sujeitos do que outros, revelando que "a desigualdade ambiental tem especificidade racial" (Acselrad, 2004, p. 31), como denuncia a concepção do racismo ambiental.

O termo racismo ambiental foi usado pela primeira vez por Benjamim Chavez na Carolina do Norte (Estados Unidos), em 1978, durante os protestos contra o depósito de bifenilpoliclorados (PCB), compostos altamente tóxicos (Roberts; Toffolon-Weiss, 2004). Entende-se por racismo ambiental qualquer política, prática ou diretiva conduzida por instituições governamentais, jurídicas, econômicas, políticas e militares que afete ou prejudique racialmente, de formas diferentes, voluntária ou involuntariamente, as condições ambientais de moradia, trabalho ou lazer de pessoas, grupos ou comunidades (Bullard, 2005).

Nesse sentido, vale destacar alguns pontos: primeiro, que o "o racismo ambiental não se refere apenas às ações que têm uma intenção racista, mas inclui também ações que têm um impacto racista, independente de sua intenção" (Roberts; Toffolon-Weiss, 2004, p. 81); segundo, que o racismo ambiental é uma forma de racismo institucional, uma vez que a omissão de políticas públicas favorece que no meio ambiente vigorem determinantes da desigualdade social e racial, resultando em iniquidades raciais, exploração política e enfrentamento dos piores problemas ambientais pelas comunidades negras (Bullard, 2004; Acselrad, 2004).

Importa ressaltar também que a vivência em condições socioambientais precarizadas, somadas às desigualdades de poder nos processos decisórios, constitui processos do escopo do racismo ambiental (Bullard, 2004). Sem perder de vista ainda que o baixo nível de renda, tanto individual quanto domiciliar, tem espacializado a população negra em áreas cujo "entorno seja deficiente, desgastante e produtor de doença” (Brasil, 2013, p. 13), marcado por "características indesejáveis de habitação", ou seja, pela inadequação/inexistência dos serviços de saneamento básico e energia elétrica, alta densidade populacional e construção de habitações com materiais precários.

Desse modo, estão incluídas no debate do racismo ambiental as carências de saneamento que afetam a saúde e as vidas tanto das populações negras urbanas de favelas, periferias e subúrbios quanto das populações negras tradicionais do campo, da floresta e das águas, como quilombolas, caiçaras, marisqueiras, pescadores, extrativistas, quebradeiras de coco, ribeirinhos e seringueiros. Tais vivências sanitárias marcadas por condições ambientais insalubres (na moradia, trabalho ou lazer) incluem: não acesso à água (potável ou não) e às instalações sanitárias; disputa pelo uso da água e privatização indevida de recursos hídricos; lançamento de esgoto e poluição no corpo hídrico; disposição inadequada e lançamento clandestino de resíduos (domésticos ou tóxicos); moradias em encostas perigosas ou em beiras de cursos d'água sujeitas a deslizamentos e enchentes; e vivência em lixões, áreas de enchentes, vazadouros de lixo e aterros de lixo químico.

\section{A saúde ambiental em saneamento da população negra do Brasil Colônia ao Brasil atual}

As condições de saneamento constituem, então, um mote importante nos contextos de racismo ambiental, cuja historicidade remete ao Período Colonial, quando a população negra escravizada já não tinha acesso a saneamento e realizava os serviços de saneamento de casas-grandes, sobrados, repartições públicas e da cidade (Chalhoub, 1996; Conrad, 1985; Karasch, 200o; Klein, 1987). Isto é, os corpos negros eram os próprios sistemas de saneamento da cidade.

morfobiológico, enquanto o da etnia é sociocultural, histórico e psicológico. E, apesar de não serem sinônimas, o racismo, enquanto ideologia, opera - parasita, segundo o autor - tanto sobre a raça quanto sobre a etnia, de forma a hierarquizar, desumanizar e justificar a discriminação existente. 
O contexto colonial, portanto, foi determinante e fundante (e fulminante) no quadro epidemiológico da população negra, afetando suas condições de higiene e saúde ao instituir as doenças relacionadas ao saneamento ambiental inadequado (DRSAI), conceito cunhado por Costa et al. (2004) baseados nas classificações da Organização Mundial da Saúde (OMS, 1985, 1997), também denominadas de doenças relacionadas ao abastecimento de água e ao esgoto, ${ }^{7}$ de acordo com o Manual de saneamento (Funasa, 2015).

A mortalidade por doenças ligadas às condições precárias de saneamento e higiene marcou a historiografia do tráfico negreiro e dos superlotados e insalubres navios tumbeiros, seja pelas instalações sanitárias e de higiene rudimentares, seja pelas condições da comida e da água de consumo. Estima-se que de 1 a 2 milhões de africanos tenham perdidos suas vidas na travessia forçada do transatlântico, sendo a precariedade de saneamento a responsável pela disenteria (cólera), a maior causa de morte durante essas viagens (Chalhoub, 1996; Conrad, 1985; Klein, 1987).

As condições insalubres também estiveram presentes no período de quarentena e no mercado negreiro, situações nas quais a alta mortalidade em decorrência das péssimas condições de higiene e saneamento que, somadas às más condições de alimentação, também favoreceram a proliferação de mosquitos, sujeiras e doenças epidêmicas. Após o processo de venda dessas pessoas, tais condições sanitárias eram agravadas por habitações precárias, como porões escuros e úmidos ou minúsculos cubículos, muitas vezes infestados por ratos e insetos (Farias et al. 2006; Karasch, 200o; Silva, 1988).
Além disso, muitos negros escravizados moravam e trabalhavam em locais onde proliferavam mosquitos transmissores de malária, como pântanos, áreas de alagamento das chuvas, áreas de despejo de lixo e dejetos, depósitos, cemitérios, hospitais e prisões. Assim, locais de trabalho sem sistema de drenagem e de esgotamento sanitário, sem latrinas ou banheiros e ruas lotadas tanto de excrementos animais e humanos quanto de animais e negros escravizados mortos foram determinantes para o quadro de morbimortalidade dessa população (Karasch, 200o).

Consequentemente, as principais doenças eram infecto-parasitárias, como tuberculose, disenteria, varíola, tétano e malária, agravadas pelas péssimas condições de vida, moradia, alimentação e trabalho. Diarreia, gastroenterite, hepatite e enterite ceifaram a vida de milhares de cativos, com destaque para a cólera. Doenças por vermes também foram fatais para a população negra já que, com alimentação precária, o ciclo de reprodução da ancilostomíase quase sempre terminava com a morte do hospedeiro negro. A disenteria bacilar, por exemplo, era uma das doenças mais velozes e fatais, levando a óbito em três ou quatro dias, enquanto a disenteria amebiana era mais recorrente, com maior probabilidade de sobrevivência (Farias et al., 2006; Karasch, 200o).

Nesse momento, a expectativa de vida de uma pessoa negra era de 23 anos, sendo que um terço não sobrevivia antes de completar um ano de idade e quase metade das crianças não conseguia ultrapassar os 5-10 anos de idade. O saneamento inexistente, somado ao hábito de brincar em ruas cheias de fezes e de colocar terra na boca, propiciou que muitas crianças fossem infectadas por bichodo-pé, lombrigas, oxiurose e ancilostomose.

\footnotetext{
7 Compreende-se por DRSAI (Costa et al., 2004) enfermidades relacionadas à água, excreta e lixo, além dos grupos de doenças infectoparasitárias (DIP) e de doenças infecciosas intestinais (DII), a saber: (1) doenças de transmissão feco-oral: diarreias, febres entéricas e hepatite A; (2) doenças transmitidas por inseto vetor: dengue, febre amarela, leishmanioses (tegumentar e visceral), filariose linfática, malária e doença de Chagas; (3) doenças transmitidas pelo contato com a água: esquistossomose e leptospirose; (4) doenças relacionadas com a higiene: doença dos olhos, tracoma, conjuntivites, doenças da pele e micoses superficiais; (5) geo-helmintos e teníases: helmintíases e teníases. Segundo o Manual da Funasa (2015), por sua vez, são doenças relacionadas ao abastecimento de água: (1) doenças diarreicas e verminoses: cólera, giardíase, criptosporidíase, febre tifoide, febre paratifoide, amebíase, hepatite infecciosa (vírus: "A” e "B”) e ascaridíase; (2) doenças de pele: impetigo, dermatofitose e micoses, escabiose e piodermite; (3) doenças dos olhos: conjuntivites (vírus e bactérias); (4) transmitidas por vetores: malária, dengue, febre amarela e filariose; (5) associada à água: esquistossomose e leptospirose. Constituem doenças relacionadas ao esgoto: (1) bactérias: febre tifoide e paratifoide, cólera e diarreia aguda; (2) vírus: hepatite A e E, poliomielite e diarreia aguda; (3) protozoário: diarreia aguda e toxoplasmose; (4) helmintos: ascaridíase, tricuríase, ancilostomíase, esquistossomose, teníase e cisticercose.
} 
Por conta das condições de maior vulnerabilidade, crianças e idosos eram as maiores vítimas dos óbitos por diarreia e das doenças relacionadas à inadequação em saneamento (Karasch, 2000; Klein, 1987).

No século XIX, muitas pessoas negras escravizadas ainda morriam de diarreia, vermes e parasitas. Segundo Karasch (2000, p. 239),

o que de fato debilitava e matava os escravos, especialmente as crianças, não era o verme por si, mas a combinação de desnutrição e vermes (e talvez parasitas da malária), da qual a anemia e diarreia eram amiúde os únicos sintomas.

Tais condições propiciavam que muitas outras perturbações gastrointestinais, além de vermes e parasitas, provocassem diarreia e contribuíssem para piorar as condições de saúde da população negra escravizada. A hepatite, por exemplo, que também ocorre em ambientes com condições sanitárias deficientes, era muito comum e se somava aos baixos padrões socioeconômicos, à nutrição deficiente, ao forte estresse e ao excesso de trabalho, contribuindo para o quadro de alta mortalidade por essas doenças (Karasch, 200o).

No início do século XXI, organizou-se uma agenda voltada para a saúde da população negra brasileira, mobilizada sobretudo pelos movimentos negros, denunciando as injustiças e iniquidades em saúde nessa parcela da população brasileira ocasionadas pela omissão do Estado, que resultou na PNSIPN, focando a equidade racial em saúde (Brasil; Trad, 2012). Outros importantes marcos legais foram estabelecidos, como a Declaração e o Plano de Ação da Conferência de Durban (Conferência..., 2001), a lei de saneamento (Brasil, 2007) e o Estatuto da Igualdade Racial (Brasil, 2010), que recomendam e asseguram que as populações negras urbanas (de favelas, cortiços e áreas urbanas subutilizadas, degradadas ou em processo de degradação) e tradicionais (como quilombolas, ribeirinhos e outros) tenham prioridade nos programas de saneamento.

Apesar disso, ainda hoje a realidade de significativa parcela da população negra brasileira sobrevive em condições sanitárias semelhantes ao
Brasil Colonial. Desse modo, no cenário brasileiro revelado pelo Censo 2010, verificou-se que $48 \%$ da população brasileira era branca e 51\% era negra. No entanto, essas porcentagens não se mantiveram na análise das condições de saneamento, evidenciando uma sobre-representação da população negra nas condições ambientais insalubres de moradia, uma vez que $61 \%$ da população sem cobertura do abastecimento de água era negra e apenas $37 \%$ era branca; $67 \%$ da população sem acesso à coleta dos resíduos era negra e apenas 30\% era branca; $58 \%$ da população sem cobertura do esgotamento sanitário era negra e 40\% era branca; e $76 \%$ da população sem banheiro era negra e apenas $20 \%$ era branca.

Em termos absolutos, significa dizer que no Brasil, em 2010, havia 21.532.754 pessoas negras cujo abastecimento de água ocorria por poço, nascente, carro-pipa, armazenamento da água da chuva, rios, açudes, lagos, igarapés ou outras formas. Havia 17.955.295 pessoas negras que queimavam, enterravam ou jogavam seu lixo em terreno baldio, logradouro, rio, lago ou mar, ou ainda outras formas de destino. Havia 48.572.734 pessoas negras cujos esgotos eram destinados em fossa séptica, fossa rudimentar, vala, rio, mar, lago ou outras formas; ou, ainda, 10.610.966 pessoas negras sob a condição alarmante e precária de não terem sequer banheiro no domicílio, conforme Figura 1.

Dessa maneira, verifica-se a importância do racismo ambiental na produção de uma realidade marcada pela insalubridade ambiental, na medida em que o saneamento é um dos fatores de promoção desta, isto é, fornece condições materiais e sociais que asseguram o pleno gozo de saúde e bem-estar por inibição, prevenção ou impedimento de endemias e epidemias veiculadas pelo meio ambiente (Funasa, 2015). Na prática, esses dados evidenciam o abismo racial na oferta de políticas públicas de saneamento, revelando uma linha proporcional entre precarização do serviço prestado e enegrecimento da população não atendida, expondo a população negra a formas precarizadas de acesso à água e de destinação do esgoto e do lixo e, consequentemente, tornando-a mais vulnerável a riscos à saúde. 
Figura I - Perfil racial da inadequação em saneamento básico, Brasil, 2010

\section{Com abastecimento de água}

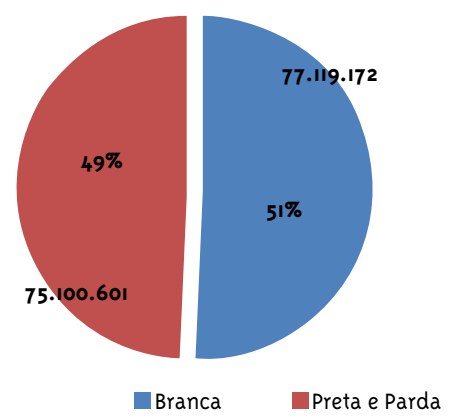

Com esgotamento sanitário

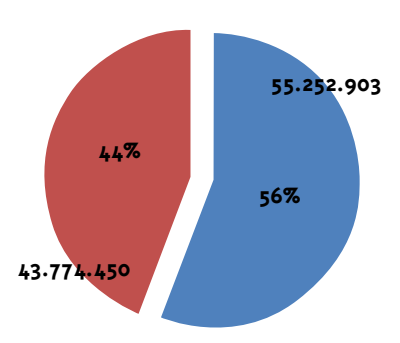

Branca Preta e Parda

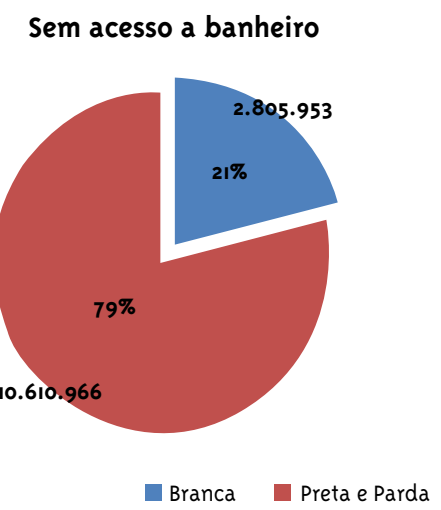

Sem abastecimento de água

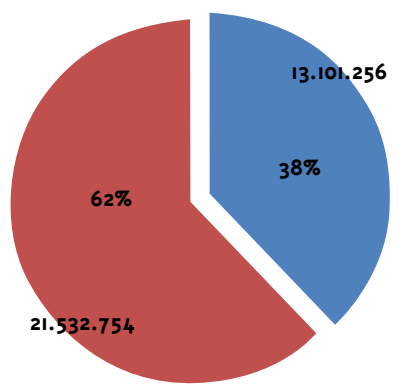

Poço,nascente,carro-pipa,água da chuva armazenada, rios, açudes, lagos, igarapés ou outras formas

\section{Sem esgotamento sanitário}

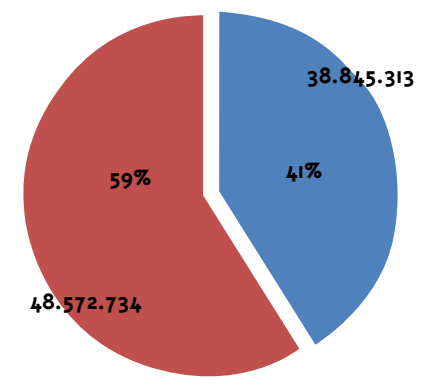

Fossa séptica, fossa rudimentar, vala, rio, mar, lago ou outras formas

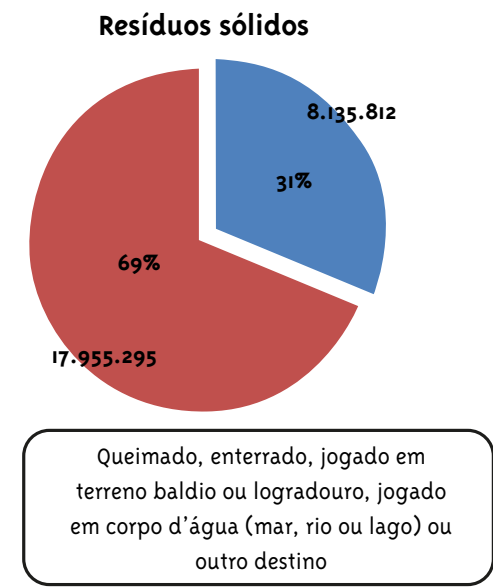

Fonte: Adaptado de IBGE (2010) com colaboração de Antônio Tadeu Ribeiro de Oliveira (IBGE/RJ). 
Isso se verifica nos dados do DataSUS (Brasil, 2006). De 1996 a 2014, 231.087 brasileiros morreram de DRSAI. Dessas mortes, 23\% não apresentam a identificação racial, e dos $77 \%$ cujo quesito cor fora preenchido, 55\% são negras e $43 \%$, brancas, uma diferença percentual de $12 \%$ que equivale a 21.270 óbitos a mais. $\mathrm{O}$ acumulado de óbitos da população negra no Brasil por estas $\mathrm{DRSAI}^{8}$ nesse período é de 97.897 pessoas, o equivale à queda de 710 aviões, ${ }^{9}$ morrendo por doenças evitáveis do século XVI. Ou seja, é como se 40 aviões caíssem anualmente com uma tripulação negra a bordo, tendo o Estado como piloto, as instituições sociais como copilotos e a sociedade como comissária de bordo.

Em termos práticos, significa que uma pessoa negra morre a cada uma hora e meia por falta de saneamento no Brasil. É importante ressaltar, conforme Figura 2, que 50\% de cada Boeing dessa tripulação rumo à morte tem seus assentos ocupados por bebês de até um ano de idade (13,34\%, o que equivale a 687 bebês negros/ano) e idosos negros (acima de 60 anos, somando $36 \%$, o que equivale a 1.865 idosos negros/ano). Assim como no período colonial, crianças e idosos negros seguem mais vulnerabilizados.

Nesse panorama, as condições de vida da população negra (e indígena) seguem sendo vulnerabilizadas, marginalizadas e minimizadas, produzindo histórico-cotidianamente condições precárias de viver. E, como se não bastasse o genocídio por homicídios dos jovens negros de periferia, a morte por saneamento tem afetado enormemente bebês e idosos negros, além dos jovens. É como se morrer fosse o nosso destino, na infância por saneamento, na juventude por bala, na velhice por saneamento.

É importante destacar que a previsão é de que a realidade da população negra seja ainda pior no que se refere ao acometimento de doenças e evolução até o óbito por DRSAI, uma vez que muitos casos são subnotificados e que $23 \%$ (valor significativo a nível estatístico) dos casos que se enquadram na categoria "sem informação" podem ter sido negligenciados pelo racismo institucional - além do fato de que o público majoritário do SUS é negro, assim como a população sem saneamento, conforme Figura 1. Ainda assim, os números são expressivos.

Merece nota ainda a consideração de que o número de pessoas negras que adoecem por não ter saneamento é ainda maior: apenas de janeiro de 2008 a outubro de 2016 , quase 2 milhões foram internadas por doenças de saneamento no Brasil (Brasil, 2016), considerando apenas os dados oficiais e descartando as subnotificações.

Esse contexto revela, como aponta Werneck (2016), que as decisões de política e gestão da saúde têm sido insuficientes ou ineficientes na redução e eliminação das vulnerabilidades que afetam a saúde e a qualidade de vida da população negra, inclusive no tratamento desigual produzido ou sustentado pelo SUS, e fazem aumentar sua vulnerabilidade frente aos direitos humanos a partir do racismo institucional. "No caso da saúde da população negra, o meio ambiente, que exclui e nega o direito natural de pertencimento, determina condições especiais de vulnerabilidade" individual, social e programática, derivada de fenômenos socioculturais, políticos e econômicos (Lopes, 2005a, p. 55).

\footnotetext{
8 Estão consideradas aqui tanto as doenças diretamente relacionadas à falta de saneamento quanto aquelas agravadas por não se ter saneamento adequado para a higiene pessoal. Isto é, além das doenças de transmissão feco-oral e por contaminação da água, estão consideradas as causadas por vetores associados à falta de saneamento e condições ambientais insalubres. Assim, as enfermidade consideradas são: cólera, febres tifoide e paratifoide, amebíase, diarreia e gastroenterite com origem infecciosa presumida, tuberculose respiratória com confirmação bacteriológica e histológica, tuberculose das vias respiratórias sem confirmação bacteriológica e histológica, febres transmitidas por mordedura de rato, leptospirose, hanseníase, dengue, febre hemorrágica devido ao vírus da dengue, febre amarela, hepatite aguda A, malária por Plasmodium falciparum, malária por Plasmodium vivax, malária por Plasmodium malariae, outras formas de malária confirmadas por exames parasitológicos, malária não especificada (NE), leishmaniose, esquistossomose, filariose, ancilostomíase, ascaridíase, estrongiloidíase, tricuríase, oxiuríase, outras helmintíases intestinais não classificadas em outra parte (NCOP), parasitose intestinal NE, outras helmintíases, sequelas de tuberculose e sequelas de hanseníase.

9 Cálculo realizado segundo o modelo Boeing 737-70o, utilizado pela companhia Gol e com capacidade de 138 passageiros.
} 
Figura 2 - Perfil racial de mortalidade por DRSAI, Brasil, 1996 a 2014

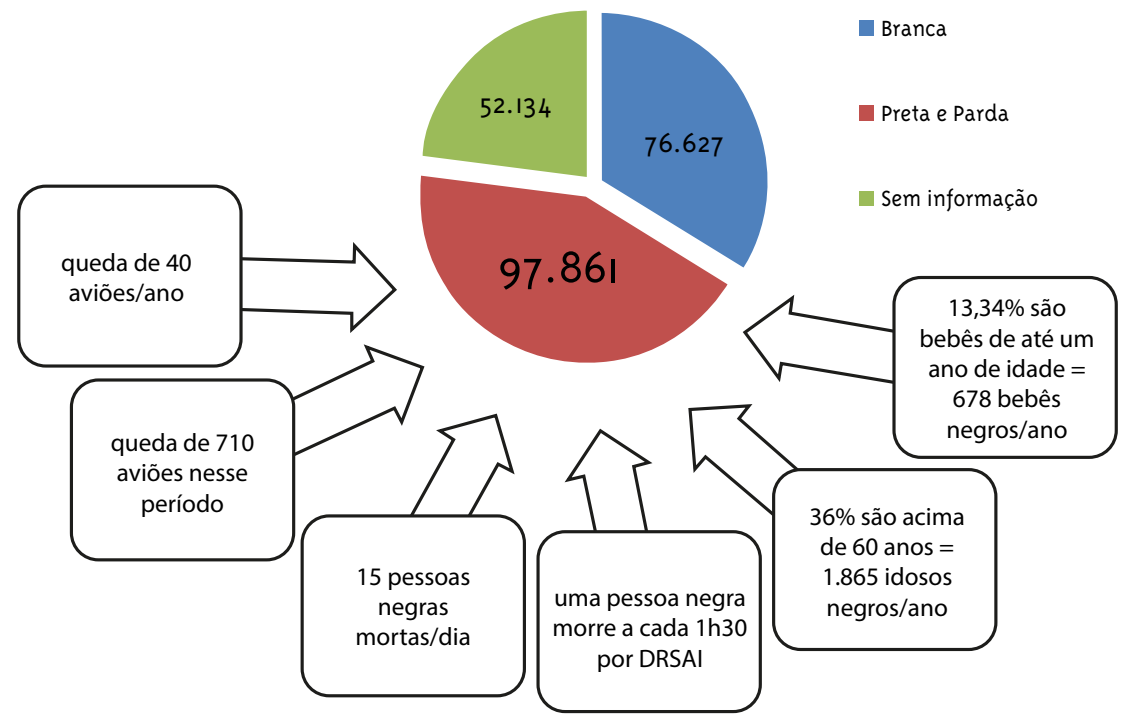

Fonte: Adaptado de Brasil (2016).

Desse modo, as vivências marcadas pelo racismo ambiental expõem a população negra a riscos e condições em virtude de as tomadas de decisões ambientais e planejamento urbano não considerarem tal grupo, promovendo destruição ecológica e explorando a vulnerabilidade dessas populações destituídas de direitos econômicos e políticos. Uma situação que é impregnada pelo legado da escravidão e pela resistência branca à justiça equitativa (Bullard, 2004, 2005).

Como se verifica, então, o racismo é um importante fator de distribuição seletiva das pessoas no ambiente físico, no uso do solo, nos padrões habitacionais e no desenvolvimento de infraestrutura, de tal forma que ele tem sido determinante na explicação das condições das favelas do Brasil, por exemplo, e na oferta deficiente de infraestrutura em saneamento, saúde, segurança e transporte público à população negra residente. Dessa maneira, o racismo tem privilegiado brancos e explicado a iniquidade social, a exploração política, a segregação social e a falta de saúde e bem-estar da população negra brasileira (Bullard, 2004).

Por fim, é importante situar que a degradação ambiental interfere diretamente nas possibilidades dignas de existência do ser humano, exposto a condições insalubres de racismo ambiental em que a própria população negra é tratada como insalubre por parcelas da sociedade e do Estado. É importante compreender e atuar em prol da dimensão ecológica da dignidade humana de populações privadas de direitos básicos de sobrevivência e de qualidade de vida e impactadas pelo racismo ambiental, afinal, como lembra Lopes (2005a), a promoção da equidade racial passa necessariamente pela garantia da saúde e da dignidade como direitos humanos.

\section{Considerações finais}

O racismo ambiental e a saúde ambiental em saneamento são de extrema relevância na compreensão do quadro epidemiológico da saúde da população negra, na medida em que se verifica que há um perfil racial no não acesso ao saneamento e, consequentemente, na mortalidade por DRSAI. Por isso, a politização dos processos de saúde-doença é essencial para compreensão das múltiplas faces do racismo como determinante social da saúde, num contexto de "doenças da pobreza", "doenças negligenciadas" e "doenças evitáveis" que fornecem pistas das dimensões sociais, econômicas e políticas que (re)produzem um quadro político-epidemiológico 
de vulnerabilidade da saúde, do corpo e da vida da população negra, aumentando os condicionantes sociais que a expõe a riscos e determinam o seu nascer, viver, adoecer e morrer.

Desse modo, busquei mostrar como a vigência do racismo ambiental é um fato histórico que remete ao Período Colonial. Desde os navios tumbeiros aos atuais espaços negros marginalizados pelo planejamento urbano estatal (favelas, periferias, subúrbios, quebradas etc.), a população negra tem sido despojada de um direito básico, o acesso a saneamento. Verifica-se, portanto, um continuum colonial, uma continuidade das violências e desigualdades colonialistas e seus mecanismos de reatualização de não reconhecimento da população negra como sujeitos, tampouco como humanos, e, por isso, institui a ela uma política que lhe nega seus (sujeitos de) direitos e sua dignidade (humana).

Nesse contexto, o papel do Estado é vital para a manutenção dessa secular historicidade de "negligência" com as condições básicas de higiene e saúde desse grupo. Ao não garantir o direito à cidade e à saúde ambiental em saneamento para a população negra, o Estado tem utilizado o saneamento como um sofisticado dispositivo político para violentar e assassinar os corpos considerados matáveis, tanto ao se ausentar do papel de promoção à saúde via políticas públicas quanto na precarização do SUS, que não consegue atender e reverter o quadro de mortalidade por DRSAI.

Explicita-se, então, um cenário de genocídio eugenista, isto é, uma produção racializada da morte em massa via violência do Estado e seus mecanismos de (bio/necro) controle racial, responsáveis por instituir uma política de morte, limpeza racial e embranquecimento da sociedade brasileira. Uma política higienista e eugenista que tem perdurado séculos e cuja marca é a produção de vulnerabilidades políticas, materiais e simbólicas por meio de ações, discursos, estigmas, "omissões" e condições onde/quando o corpo negro é tido como desprezível, descartável e matável, simultaneamente à violação de sua saúde, cidadania e dignidade.

Essa negação de direitos humanos (tão básicos e fundamentais) pela "negligência" do Estado, que caracteriza o racismo institucional, coloca a discussão do racismo ambiental na arena do poder, uma vez que as mesmas populações negras impactadas pela "omissão" do Estado são excluídas também dos espaços e processos deliberativos e decisórios de poder, como na elaboração e fiscalização das políticas urbanas (ambientais, de saúde e habitacionais, dentre outras) de seu interesse. Obviamente, essa destituição política também está implicada na dimensão material, já que esse contingente populacional também é desprovido de condições econômicas que propiciem melhorias ambientais no seu domicílio ou para habitarem locais com infraestrutura em saneamento. Isso significa que há dupla destituição nas vivências marcadas pelo racismo ambiental, a de poder e a material (há ainda uma dimensão simbólica e subjetiva não tratada neste artigo, que diz respeito ao negro sujo, imundo, fedido).

Vale destacar ainda que essa "negligência", na verdade, consiste no próprio racismo institucional e subjetivado. Verifica-se uma autodesresponsabilização do Estado no seu papel social, afinado às perspectivas (neo)liberais, mas também coloniais, quando já vigorava a lógica desumana, desigual, exploratória e degradante do Estado em detrimento do meio ambiente e das populações negras e indígenas. Não é mera “negligência”, portanto, ao acaso, desproposital e inconsciente, mas uma política cuja finalidade é a manutenção do poder e do status quo, uma vez que há objetividade, racionalidade e operacionalidade nesse racismo institucional metamorfoseado de "negligência”. Isso porque, ao negligenciar a variável racial como fator de desigualdade e critério de alocação de políticas públicas, as desigualdades raciais seguem não mensuradas e, portanto, não combatidas, reatualizando e invisibilizando o continuum colonial de produção e reprodução do racismo institucional em suas diversas faces.

Dito de outro modo, a "negligência" das políticas sociais tem sido retroalimentada pela "negligência" acadêmico-científica, o que torna esse um problema social histórico no Brasil ao mesmo tempo em que não tem sido alçado a problema sociológico pelas pesquisas. Apesar de uma pessoa negra morrer por falta de saneamento a cada uma hora e meia, nossas mortes têm sido silenciadas, banalizadas, naturalizadas e produzidas com consentimento (mas sem sentimento). 0 racismo ambiental e seu impacto 
na saúde ambiental da população negra ainda seguem silenciados nas pesquisas das ciências sociais em saúde e o saneamento, enquanto mecanismo de atualização do racismo institucional (e ambiental), ainda tem escapado à produção científica e à atuação de movimentos e coletivos negros do país.

Tendo isso em vista, o não acesso a saneamento e a mortalidade por DRSAI segundo raça constituem potentes indicadores de desigualdade racial que devem ser explorados em programas, políticas públicas e análises, na medida em que o saneamento têm se constituído como privilégio (e não direito) e mecanismo de controle racial. Por isso, é importante que a PNSIPN inclua as DRSAI em seu escopo de atenção e atuação, de tal modo que a relação raça e DRSAI seja considerada como indicador de mensuração de desigualdades e critério de planejamento para priorizar áreas mais insalubres nas tomadas de decisão para alocação de políticas públicas (de saneamento, de saúde e outras questões sociais).

É fundamental também pesquisas quantiqualitativas que aprofundem esta análise exploratória, tanto na escala do cotidiano quanto na local/regional, seja por estudos de caso ou comparativos, cujos recortes temporais e espaciais exponham as proporções de doenças e populacionais segundo raça. Isso exige, ainda, que as bases de dados das instituições públicas nacionais (como a base completa do DataSUS e do IBGE - aglomerados subnormais, Pesquisa Nacional por Amostra de Domicílio (PNAD) e Censo, por exemplo) tornem acessível a possibilidade de cruzamento de dados com a variável cor/raça, cujo acesso é restrito ou inexistente, para que se possa construir pesquisas e teorias que visibilizem e ampliem a compreensão dos mecanismos do racismo institucional e ambiental.

Enfim, urge olhares e ações que coloquem o racismo ambiental e a saúde ambiental em saneamento da população negra nas agendas políticas e de pesquisa. A compreensão da importância e do impacto do saneamento na saúde da população negra e o fortalecimento do controle social de coletivos e movimentos sociais negros nos processos decisórios e deliberativos de políticas que impactem suas condições de vida, moradia e trabalho são condições urgentes para reversão desse quadro histórico de iniquidades e desigualdades raciais. Garantir a saúde ambiental em saneamento da população negra, portanto, é condição básica para efetivar a cidadania-democracia brasileira e a humano-dignidade de uma população que ainda vivencia as marcas instituídas pelo colonialismo em pleno Estado Democrático de Direito.

\section{Referências}

ACSELRAD, H. Justiça ambiental: ação coletiva e estratégias argumentativas. In: ACSELRAD, H.; HERCULANO, S.; PÁDUA, J. A. (Org.). Justiça ambiental e cidadania. Rio de Janeiro: Relume Dumará, 2004. p. 23-39.

BARATA, R. B. Iniquidade e saúde: a determinação social do processo saúde-doença. Revista USP, São Paulo, n. 51, p. 138-145, 2001.

BARATA, R. B. Como e por que as desigualdades sociais fazem mal à saúde. Rio de Janeiro: Editora Fiocruz, 2009.

BASTOS, J. L.; FAERSTEIN, E. Discriminação e saúde: perspectivas e métodos. Rio de Janeiro: Editora Fiocruz, 2012.

BRASIL. Constituição Federal. Constituição da República Federativa do Brasil. Brasília, DF: Senado, 1988.

BRASIL. Ministério da Saúde. Sistema de Informações sobre Mortalidade - SIM (SIM/SUS). Mortalidade - Brasil. Período: 1996-2014. Brasília, DF, 2016. Disponível em: <https://bit.ly/2y3vz6R>. Acesso em: 30 dez. 2016.

BRASIL. Lei $n^{0}$ 11.445, de 5 de janeiro de 2007. Diário Oficial [da] República Federativa do Brasil, Brasília, DF, 5 jan. 2007. Disponível em: <https://bit.ly/39c4VFQ>. Acesso em: 1 maio 2014.

BRASIL. Lei $\mathrm{n}^{0}$ 12.288, de 20 de julho de 2010. Diário Oficial [da] República Federativa do Brasil, Brasília, DF, 21 jul. 2010. Disponível em: <https://bit.ly/2WEUmIr>. Acesso em: 1 jan. 2017.

BRASIL. Secretaria de Políticas de Promoção da Igualdade Racial. Racismo como determinante social de saúde. Brasília, DF, 2011.

BRASIL. Ministério da Saúde. Política Nacional de Saúde Integral da População Negra: uma política para o SUS. 2. ed. Brasília, DF, 2013. 
BRASIL, S. A.; TRAD, L. A. B. O movimento negro na construção da Política Nacional de Saúde Integral da População Negra e sua relação com o Estado brasileiro. In: BATISTA, L. E.; WERNECK, J.; LOPES, F. (Org.). Saúde da população negra. Brasília: ABPN, 2012. p. 70-97.

BULLARD, R. Enfrentando o racismo ambiental no século XXI. In: ACSELRAD, H.; HERCULANO, S.; PÁDUA, J. A. (Org.). Justiça ambiental e cidadania. Rio de Janeiro: Relume Dumará, 2004. p. 41-68.

BULLARD, R. Ética e racismo ambiental. Revista Eco 21, Rio de Janeiro, ano XV, n. 98, 2005. Disponível em: <https://bit.ly/39hIdvH >. Acesso em: 22 mar. 2020.

CHALHOUB, S. Cidade febril: cortiços e epidemias na Corte Imperial. São Paulo: Companhia das Letras, 1996.

CNDSS - COMISSÃO NACIONAL SOBRE DETERMINANTES SOCIAIS DA SAÚDE. As causas das iniquidades em saúde no Brasil: relatório final da Comissão Nacional sobre Determinantes Sociais da Saúde. Brasília, 2008. Disponível em: <https://bit.ly/3bjTn4B>. Acesso em: 19 abr. 2018.

CONFERÊNCIA MUNDIAL CONTRA O RACISMO, DISCRIMINAÇÃO RACIAL, XENOFOBIA E INTOLERÂNCIA CORRELATA, 1, 2001, Durban. Declaração e plano de ação. Brasília: Fundação Cultural Palmares, 2001.

CONRAD, R. E. Tumbeiros: o tráfico de escravos para o Brasil. São Paulo: Brasiliense, 1985.

COSTA, A. M. et al. Impactos na saúde e no Sistema Único de Saúde decorrentes de agravos relacionados a um saneamento ambiental inadequado. In: BRASIL. Fundação Nacional de Saúde. Caderno de pesquisa de engenharia de saúde pública. Brasília, DF: Funasa, 2004. p. 5-26.

CUNHA, E. M. G. P. Recorte étnico-racial: caminhos trilhados e novos desafios. In: BATISTA, L. E.; WERNECK, J.; LOPES, F. (Org.). Saúde da população negra. Brasília, DF: ABPN, 2012. p. 37-48.

FARIAS, J. B. et al. Cidades negras: africanos, crioulos e espaços urbanos no Brasil escravista do século XIX. São Paulo: Alameda, 2006.
FUNASA - FUNDAÇÃO NACIONAL DA SAÚDE. Manual de saneamento. 4. ed. Brasília, DF, 2015.

GARCIA, A. S. Desigualdades raciais e segregação urbana em antigas capitais: Salvador, cidade d'Oxum e Rio de Janeiro, cidade de Ogum. Rio de Janeiro: Garamond, 2009.

GELEDÉS. Racismo institucional: uma abordagem conceitual. São Paulo, 2013a. Disponível em: <https://bit.ly/2wlıpvr>. Acesso em: 21 abr. 2018.

GELEDÉS. Guia de enfrentamento do racismo institucional. São Paulo, 2013b. Disponível em: <https://bit.ly/2wmLEUQ>. Acesso em: 21 abr. 2018.

GIL, A. C. Métodos e técnicas de pesquisa social. 6. ed. São Paulo: Atlas, 2009.

HELLER, L. Relação entre saúde e saneamento na perspectiva do desenvolvimento. Ciência \& Saúde Coletiva, Rio de Janeiro, v. 3, n. 2, p. 73-84, 1998.

IBGE - INSTITUTO BRASILEIRO DE GEOGRAFIA E ESTATÍSTICA. Censo 201o. Rio de Janeiro, 2010. Disponível em: <https://bit.ly/3akGdEE>. Acesso em: 23 mar. 2020.

KARASCH, M. C. A vida dos escravos no Rio de Janeiro (1808-1850). São Paulo: Companhia das Letras, 2000.

KLEIN, H. S. Vida, morte e família nas sociedades escravocratas afro-americanas. In: KLEIN, H. S. A escravidão africana: América Latina e Caribe. São Paulo: Brasiliense, 1987. p. 157-181.

LOPES, F. Experiências desiguais ao nascer, viver, adoecer e morrer: tópicos em saúde da população negra. In: BATISTA, L. E.; KALCKMANN, S. (Org.) Seminário Saúde da População Negra no Estado de São Paulo 2004. São Paulo: Instituto de Saúde, 2005a. p. 53-102.

LOPES, F. Para além da barreira dos números: desigualdades raciais e saúde. Caderno de Saúde Pública, Rio de Janeiro, v. 21, n. 5, p. 1595-1601, 2005b.

MINAYO, M. C. S. O desafio da pesquisa social. In: MINAYO, M. C. S. (Org.) Pesquisa social: teoria, método e criatividade. 32. ed. Petrópolis: Vozes, 2012. p. 9-29. 
MUNANGA, K. Uma abordagem conceitual das noções de raça, racismo, identidade e etnia. In: SEMINÁRIO NACIONAL RELAÇÕES RACIAIS E EDUCAÇÃO, Rio de Janeiro, 2003. Anais... Niterói: Penesb, 2003. Disponível em: <https://bit.ly/39hMHT3>. Acesso em: 6 dez. 2018. OMS - ORGANIZAÇÃO MUNDIAL DA SAÚDE. Manual da Classificação Estatística Internacional de Doenças, Lesões e Causas de Óbitos.

São Paulo, 1985.

OMS - ORGANIZAÇÃO MUNDIAL DA SAÚDE. Classificação Estatística Internacional de Doenças e Problemas Relacionados à Saúde. 10. rev. São Paulo, 1997.

PORTO, M. F. S. Saúde pública e (in)justiça ambiental no Brasil. In: ACSELRAD, H.; HERCULANO, S.; PÁDUA, J. A. (Org.). Justiça ambiental e cidadania. Rio de Janeiro: Relume Dumará, 2004. p. 119-140.

RAUPP, L. et al. Condições de saneamento e desigualdades de cor/raça no Brasil urbano: uma análise com foco na população indígena com base no Censo Demográfico de 2010. Revista Brasileira de Epidemiologia, São Paulo, v. 20, n. 1, p. 1-15, 2017.

ROBERTS, J. T.; TOFFOLON-WEISS, M. Concepções e polêmicas em torno da justiça ambiental nos Estados Unidos. In: ACSELRAD, H.; HERCULANO, S.; PÁDUA, J. A. (Org.). Justiça ambiental e cidadania. Rio de Janeiro: Relume Dumará, 2004. p. 81-95.
ROSEMBERG, F.; PINTO, R. P. Saneamento básico e raça. Revista Brasileira de Crescimento e Desenvolvimento Humano, São Paulo, v. 5, n. 1, p. 29-42, 1995.

SANTOS, S. B. Famílias negras, desigualdades, saúde e saneamento básico no Brasil. Tempus: Actas de Saúde Coletiva, Brasília, DF, v. 7, n. 2, p. 41-53, 2013.

SILVA, M. C. T. Reflexão sobre o conceito de problema social - I. Análise Social, Lisboa, v. 5, n. 17, p. 5-22, 1967.

SILVA, M. R. N. Negro na rua: a nova face da escravidão. São Paulo: Hucitec, 1988.

SOARES, S. R. A.; BERNARDES, R. S.; CORDEIRO NETTO, O. M. Relações entre saneamento, saúde pública e meio ambiente: elementos para formulação de um modelo de planejamento em saneamento. Caderno de Saúde Pública, Rio de Janeiro, v. 18, n. 6, p. 1713-1724, 2002.

SOARES FILHO, A. M. O recorte étnico-racial nos Sistemas de Informações em Saúde do Brasil: potencialidades para a tomada de decisão. In: BATISTA, L. E.; WERNECK, J.; LOPES, F. (Org.). Saúde da população negra. Brasília, DF: ABPN, 2012. p. 49-69.

WERNECK, J. Racismo institucional e saúde da população negra. Saúde e Sociedade, São Paulo, v. 25, n. 3, p. 535-549, 2016.

\section{Agradecimentos}

Agradeço ao Antônio Tadeu Ribeiro de Oliveira (IBGE/RG) pela disponibilidade do tempo e dos dados tão primorosos, e também à professora Cecília Campello do Amaral Mello (IPPUR/UFRJ), nossa interlocutora.

\section{Contribuição dos autores}

Victor de Jesus foi responsável pela concepção do projeto e escrita do artigo, incluindo a análise e a produção gráfica dos dados do IBGE.

Recebido: 19/12/2018

Reapresentado: 28/09/2019

Aprovado: 13/01/2020 